\title{
GROa expression and its prognostic implications in laryngeal squamous cell carcinoma
}

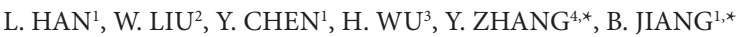 \\ ${ }^{1}$ Department of Head and Neck Surgery, Nantong Tumour Hospital, Nantong, Jiangsu, China; ${ }^{2}$ Department of Anesthesiology, Nantong Tumour \\ Hospital, Nantong, Jiangsu, China; ${ }^{3}$ Department of Otorhinolaryngology, Affiliated Hospital of Nantong University, Nantong, Jiangsu, China; \\ ${ }^{4}$ Department of Hepatobiliary Surgery, Nantong Tumour Hospital, Nantong, Jiangsu, China
}

*Correspondence: zhangyixin2222@126.com, jiangbin0692@126.com

Received March 11, 2014 / Accepted May 27, 2014

\begin{abstract}
The growth-regulated oncogene $\alpha(\mathrm{GRO} \alpha)$, which is also designated as CXC chemokine ligand 1 (CXCL1), was first identified as an autocrine growth factor in human malignant melanoma. It is involved in tumor development and invasion, and is highly expressed in various human cancers. However, little is known about the association between GROa expression and the clinical attributes of laryngeal squamous cell carcinoma (LSCC).

One-step quantitative reverse transcription-polymerase chain reaction (qRT-PCR) and immunohistochemical staining of tissue microarrays were employed to evaluate the relationship between GROa expression and LSCC clinicopathological attributes.

GROa mRNA and protein expression levels were significantly greater in LSCC than in non-cancerous tumor-adjacent tissues. GRO $\alpha$ protein expression in LSCC was also significantly associated with TNM stage, lymph node metastasis, and histopathological grade. Kaplan-Meier and Cox multi-factor analyses suggested that increased GROa expression and positive lymph node metastasis were significantly associated with the poor survival of LSCC patients.

These data indicate that GROa may be a novel prognostic marker of LSCC.
\end{abstract}

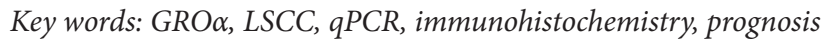

Laryngeal squamous cell carcinoma (LSCC) is the most common malignant neoplasm of the head and neck. Its incidence rate is nearly 48,000 cases in the United States and over 500,000 cases worldwide each year $[1,2]$. The most critical carcinogenic agents for LSCC are cigarette smoke and alcohol while other exogenic and endogenic factors are mostly promoters or carcinogens in multiplied carcinogenesis processes [3]. The larynx is an important organ required for pronunciation, breathing and swallowing and patients with LSCC have problems with these functions such as dysphonia, dysphagia and dyspnea. The most effective treatment of LSCC, laryngectomy, is highly invasive and is usually only performed for cases in which fundamental changes are accompanied by physiological and psychological function [4]. Despite recent advances in multidisciplinary treatment strategies for LSCC, including targeted surgical extirpation or larynx-preservation protocols implementing chemotherapy or radiotherapy, a large proportion of patients with localized or advanced disease will eventually relapse and die. Indeed, the overall survival of LSCC has not improved much for years $[5,6]$. Therefore, identifying novel molecular indicators of its malignant behavior is of great interest and could be helpful for early prevention, diagnosis and treatment of LSCC.

The growth-regulated oncogene a (GROa), a 73-aminoacid protein which is also designated CXC chemokine ligand 1 (CXCL1), was first identified as an autocrine growth factor in human malignant melanoma [7]. GRO $\alpha$ plays an important role in chemoattraction, wound healing, and angiogenesis through signaling via the seven-transmembrane G-proteincoupled receptor CXCR2 [8,9]. In recent years, GROa has been demonstrated to be involved in tumor development and invasion as a growth and anti-apoptotic factor [10-12]. It is also reported to act as a potent mediator of tumor-associated angiogenesis in bladder cancer and Kaposi's sarcoma $[13,14]$. In addition, elevated expression of GRO $\alpha$ has been detected 
in various human cancers $[10,15-18]$. In comparison, downregulation of GROa inhibits tumor growth in colorectal liver metastasis [19]. However, although GROa exhibits oncogenic characteristics, its expression and function in LSCC remain still to be fully determined. Moreover, whether GROa could be used as a biomarker for LSCC also deserves further investigation.

In the present study, the expression of GROa mRNA in LSCC tissue was detected via one-step quantitative reversetranscription polymerase chain reaction ( $\mathrm{qPCR}$ ) while the expression of GROa protein in LSCC tissue microarray (TMA) was evaluated by immunohistochemistry (IHC). The correlation between GROa expression and clinicopathological attributes of LSCC was then investigated. The results showed that GRO $\alpha$ expression was significantly elevated in LSCC in comparison with non-cancerous tumor-adjacent tissue. Its expression was also positively associated with several LSCC traits, as well as reduced patient survival. Together, our results suggest that GRO $\alpha$ is a potential biomarker for the diagnosis and prognosis of LSCC.

\section{Patients and methods}

Patient samples and clinical data. A total of 135 paraffinembedded LSCC tissue samples and 27 control samples were collected from the archives of the Department of Pathology, at the Affiliated Hospital of Nantong University, between 2002 and 2012. Diagnosis of LSCC was confirmed according to the latest WHO criteria [20] and TNM (Tumour, Node, Metastasis) stage classification (UICC 2009)[21]. The original clinical data were obtained from hospital medical records, and include details pertaining to patient gender and age, tobacco use, alcohol consumption, TNM stage, lymph node metastasis status, histopathological grade and overall survival. None of the patients received preoperative radiotherapy or chemotherapy before surgery. Written informed consent was obtained from each patient for publication of this study. Ethical approval to perform this research was approved by the Human Research Ethics Committee of the Affiliated Hospital of Nantong University.

One-step quantitative polymerase chain reaction. Ten samples of fresh LSCC tissues and matched tumor-adjacent tissues were collected from the Department of Pathology, the Affiliated Hospital of Nantong University. Total RNA was extracted from samples using Trizol reagent (Invitrogen, Carlsbad, CA). Expression levels of GRO $\alpha$ and GAPDH were determined by real-time PCR with IQ5 (Bio-Rad, Hercules, CA) using the SensiMix One-Step Kit-based SYBR Green method (Quantace, London, UK). The primers for GROa were as follows: forward primer 5'-GATTGTGCCTAATGTGTT3'and reverse primer 5'-ATCCAGATTGAACTAACTTG-3'; for GAPDH, forward primer 5'-TAT TAC CTG GAC GAG ATT CCCC-3' and reverse primer 5'-TAT TAC CTG GAC GAG ATT CCCC-3'. Amplification conditions consisted of $30 \mathrm{~min}$ at $42^{\circ} \mathrm{C}$ for reverse transcription and $2 \mathrm{~min}$ at $94^{\circ} \mathrm{C}$ for Taq activation, followed by 35 cycles of $95^{\circ} \mathrm{C}$ for $20 \mathrm{~s}, 56^{\circ} \mathrm{C}$ for $20 \mathrm{~s}$, and elongation at $72^{\circ} \mathrm{C}$ for $30 \mathrm{~s}$. Each measurement was performed in triplicate. Tissue microarray (TMA) construction and immunohistochemistry (IHC) TMAs were produced by Xinchao Biotech Co. Ltd. (Shanghai, China). Core tissue biopsies (2 $\mathrm{mm}$ in diameter) were taken from individual paraffin-embedded sections and arranged in the new paraffin blocks. The TMAs were cut into $4 \mu \mathrm{m}$ sections and placed on TMA-specific adhesivecoated glass slides. IHC analysis was performed as described previously $[22,23]$. Briefly, TMA sections were incubated with a primary monoclonal mouse anti-GRO $\alpha$ antibody (1:200, Abcam, England) diluted in phosphate-buffered saline (PBS). Following washing with PBS, sections were incubated with horseradish peroxidase-conjugated goat anti-mouse antibody (Dako Cytomation, Carpinteria, CA) for $15 \mathrm{~min}$ and then washed. The color was developed by a 15-min incubation with diaminobenzidine solution (KemEn-Tec Diagnostics, Taastrup, Denmark), and sections were weakly counterstained with hematoxylin. Negative control reactions used PBS instead of the primary antibody. The results of IHC were evaluated by a double-blind method whereby the staining results were determined under an optical microscope by two pathologists independently. In the case of disagreement, the slides were reviewed by a third pathologist until a consensus score was established. Expression levels of GRO $a$ protein were assessed by observing the incidence and staining intensity of immunohistochemically positive cells, as described previously $[22,23]$. The incidence of positive cells was scored as follows: negative as $0 ; 1-10 \%$ positive cells as 1 point; $10-50 \%$ positive cells as 2 points; and $>50 \%$ positive cells as 3 points. Staining intensity was scored as: no color as 0 ; yellow for weak positive as 1 point; light brown for medium positive as 2 points; and brown for strong positive as 3 points. The two components were produced to obtain an overall expression score, as follows: 0 as (-); $1-3$ as $(+) ; 4-6$ as $(++)$; and7- 9 as $(+++)$.The degree of GROa staining was quantified using a two-level grading system, and staining scores were defined as follows: 0-3, low expression, and 4-9, high expression.

Statistical analysis. The mRNA expression of GROa in fresh LSCC tissues compared with that of matched tumoradjacent tissues was analyzed by the Wilcoxon signed rank nonparametric test. The influence of GROa expression on clinicopathological attributes of LSCC was analyzed by the chi-square test. The Kaplan-Meier method was employed to evaluate the association between GRO $\alpha$ expression and LSCC prognosis. Univariate and multivariate analyses were executed by Cox proportional hazards regression models to determine factors that were independently associated with overall survival. For all analyses, a $p$ value less than 0.05 was regarded as statistically significant. All statistical analyses were performed using STATA Version 12.0 (Stata Corporation, College Station, TX) and SPSS 18.0 statistical software (SPSS Inc., Chicago, IL). 


\section{Results}

Clinicopathological attributes of LSCC patients. The main clinicopathological attributes of LSCC are shown in Table 1. A total of 135 LSCC patients, of median age 60 years (range 42-79 years) were enrolled in this study. Seventy-four patients had a history of cigarette use while the remaining 33 did not smoke. Fifty-two patients drank alcohol while the other 54 had never drunk. Regarding tumor TNM stage, 13 patients were stage I, 57 were stage II, and the 33 other patients were stages III and IV. In terms of histopathological grade, 11 patients were low grade, 59 were moderate grade and 61 were high grade. There were 20 patients with positive lymph node metastasis while 114 were negative.

Analysis of GROa mRNA expression in LSCC by qPCR. To assess the expression profile of GRO $a$ in LSCC, total RNA was extracted from LSCC tissues and non-cancerous tumoradjacent tissues then GRO $a$ mRNA expression was evaluated by one-step qPCR analysis. When normalized to GAPDH, the mean expression of GROa mRNA in LSCC and corresponding tumor-adjacent tissues was $88.03 \pm 28.186$ and $25.64 \pm 7.194$, respectively $(\mathrm{F}=4.599, p=0.046)$. Therefore, GROa expression was on average 3.43 -fold greater in LSCC samples than in non-cancerous tissues (Figure 1).

Detection of GROa expression in LSCC by IHC. IHC analysis was performed to investigate the expression of GRO $\alpha$ in LSCC. A significant difference was detected between GROa expression in LSCC tissues and normal tumor-adjacent tissues; indeed, elevated GRO $a$ expression was detected in 81 of $135(60 \%)$ LSCC tissues, while only six cases of 27 normal tumor-adjacent tissues (22.2\%) exhibited GROa expression $(p<0.05)$. Analysis of the GROa expression pattern revealed that positive staining was mainly localized in the cytoplasm of LSCC cells while strong staining was not observed in the non-cancerous tumor-adjacent areas. Typical IHC staining patterns of GROa in LSCC are shown in Figure 2.

Association between GROa expression and clinical attributes

The associations between expression of GRO $\alpha$ protein and the clinical attributes of LSCC patients are shown in Table 1. Elevated GROa expression was significantly associated with TNM stage $(p=0.035)$, lymph node metastasis $(p=0.018)$ and histopathological grade $(p=0.001)$. In contrast, no correlation was detected between GRO $\alpha$ expression and other

Table 1. Association of GRO a expression with clinical attributes of LSCC

\begin{tabular}{|c|c|c|c|c|c|}
\hline \multirow{2}{*}{ Groups } & \multirow{2}{*}{ No. } & \multicolumn{2}{|c|}{ GROa } & \multirow{2}{*}{$x^{2}$} & \multirow{2}{*}{$p$ value } \\
\hline & & High expression (\%) & Low expression (\%) & & \\
\hline Total & 135 & $81(60.0)$ & $54(40.0)$ & & \\
\hline \multicolumn{6}{|l|}{ Age(years) } \\
\hline$\leq 60 \mathrm{y}$ & 46 & $25(55.3)$ & $21(45.7)$ & 0.9288 & 0.335 \\
\hline$>60 \mathrm{y}$ & 89 & $56(62.9)$ & $33(37.1)$ & & \\
\hline \multicolumn{6}{|c|}{ Tobacco consumption } \\
\hline Yes & 74 & $53(71.6)$ & $21(28.4)$ & 0.1283 & 0.720 \\
\hline No & 33 & $24(75.8)$ & $8(24.2)$ & & \\
\hline Unknown & 29 & $4(13.8)$ & $25(86.2)$ & & \\
\hline \multicolumn{6}{|c|}{ Alcohol consumption } \\
\hline Yes & 52 & $38(73.1)$ & $14(26.9)$ & 0.0097 & 0.921 \\
\hline No & 54 & $39(72.2)$ & $15(27.8)$ & & \\
\hline Unknown & 29 & $4(13.8)$ & $25(86.2)$ & & \\
\hline \multicolumn{6}{|l|}{ TNM stage } \\
\hline Stage I & 13 & $9(69.2)$ & $4(30.8)$ & 4.4303 & $0.035^{\star}$ \\
\hline Stage II & 57 & $39(68.4)$ & $18(31.6)$ & & \\
\hline Stage III, IV & 33 & $29(87.9)$ & $4(12.1)$ & & \\
\hline Unknown & 32 & $4(12.5)$ & $28(87.5)$ & & \\
\hline \multicolumn{6}{|c|}{ Lymph node metastasis } \\
\hline Yes & 20 & $17(85.0)$ & $3(15.0)$ & 5.6104 & $0.018^{\star}$ \\
\hline No & 114 & $65(57.0)$ & $49(43.0)$ & & \\
\hline Unknown & 1 & $0(0.0)$ & $1(100.0)$ & & \\
\hline \multicolumn{6}{|c|}{ Histopathological grade } \\
\hline High & 61 & $28(45.9)$ & $33(54.1)$ & 15.5373 & $0.001^{\star}$ \\
\hline Moderate & 59 & $42(71.2)$ & $17(28.8)$ & & \\
\hline Low & 11 & $11(100.0)$ & $0(0.0)$ & & \\
\hline Unknown & 4 & $0(0.0)$ & $4(100.0)$ & & \\
\hline
\end{tabular}

${ }^{*} p<0.05$ 


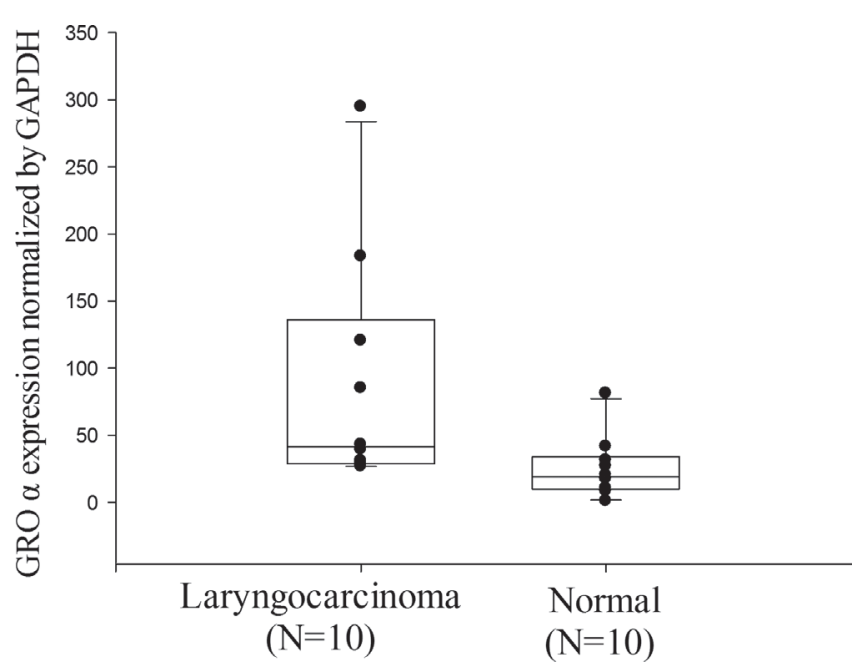

Figure 1. One-step quantitative real-time polymerase chain reaction (qPCR) evaluation of GRO $\alpha$ mRNA expression levels in LSCC (cancer) and matched tumor-adjacent tissues (non-cancerous). Glyceraldehyde 3-phosphate dehydrogenase (GAPDH) mRNA levels were used for normalization $\left({ }^{*} p=0.001\right)$.

clinical items, such as age, use of either tobacco or alcohol consumption.

Survival analysis. Univariate analysis showed that the life span of LSCC patients was correlated with elevated GROa expression ( $p=0.001$ ), TNM stage ( $p=0.003)$, and lymph node metastasis $(p=0.001)$. Multivariate analysis further revealed that both increased GRO $\alpha$ protein level $(p=0.048)$ and lymph node metastasis $(p=0.008)$ are two independent prognostic factors for overall survival (Table 2). Furthermore, KaplanMeier survival curves indicated that LSCC patients with low GRO $\alpha$ expression and negative lymph node metastasis had a significantly longer mean survival time (Figure 3 ).

\section{Discussion}

Chemokines are a huge family of chemotactic signaling molecules that are attracting increasing attention for their role in tumorigenic mechanisms within malignant cells and the tumor microenvironment. Chemokines secreted by tumors not only attract infiltrating cells into tumor sites but may also contribute to tumor cell growth [24]. Accumulating evidence has indicated that chemokines play substantial roles in the proliferation, survival, and migration of tumor cells, suggesting their involvement in tumor development and invasion [10]. The chemokine GRO $a$ was first identified as an autostimulatory melanoma mitogen from the human malignant melanoma cell line Hs0294 [25]. Multiple studies have since implicated a relationship between the expression of GROa and various human cancers [10,15-18]. Recently, it has been reported that GROa plays a critical role in human cancers through several potential signaling pathways, including NF- $\mathrm{KB}$ [26], phosphatidylinositol-3-kinase [19] and MEKK1/p38 [27].

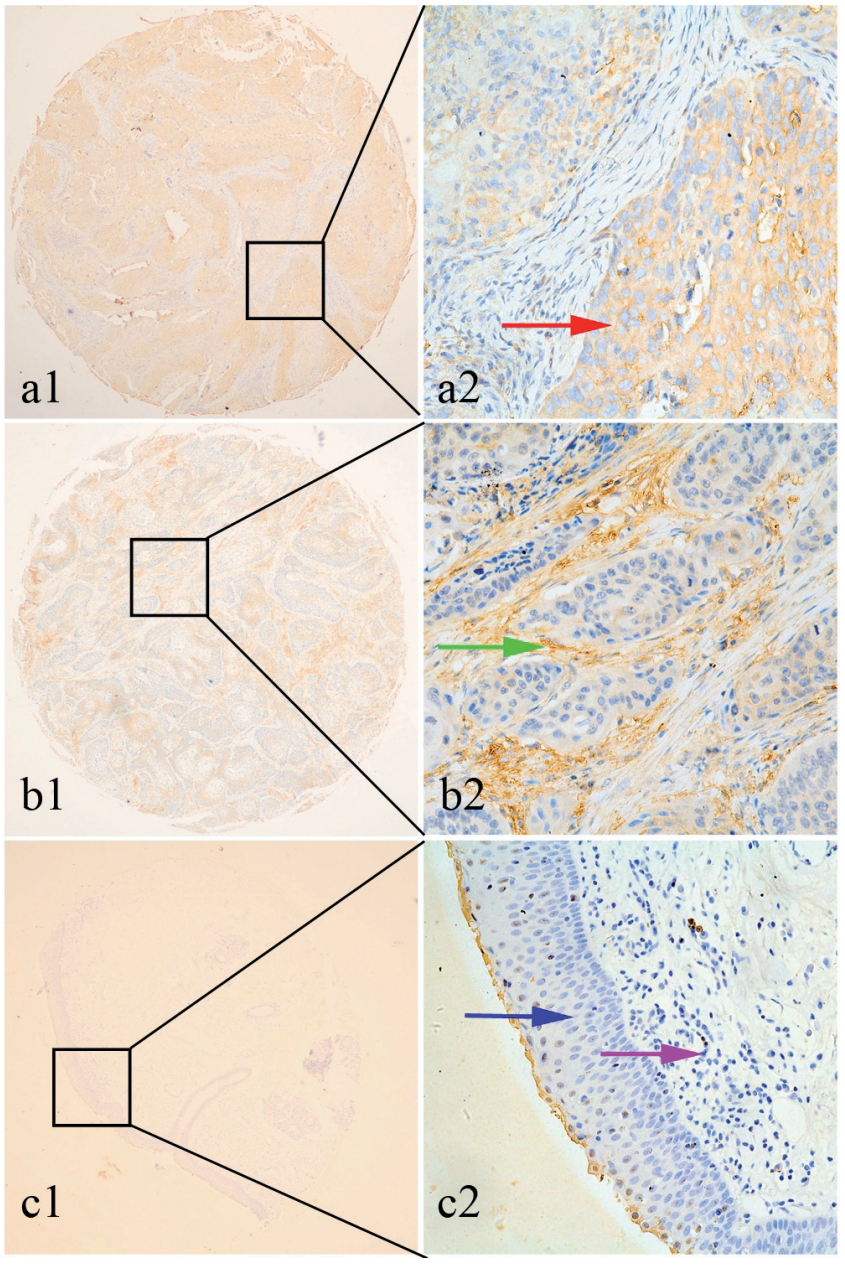

Figure 2. Representative hematoxylin-eosin (H\&E) staining and patterning of GROa protein expression in tissue microarray (TMA) sections prepared from LSCC and adjacent non-cancerous tissue. al GRO $\alpha$-positive staining in LSCC tissue sample. a2 GROa-positive staining in LSCC cytoplasm (red arrow). b1 GROa-positive staining in LSCC tissue sample b2 GROapositive staining in LSCC stromal cells (green arrow). c1 GROa-negative staining in tumor-adjacent non-cancerous tissue sample. c2 GROa-negative staining in LSCC (blue arrow) and in tumor-adjacent non-cancerous tissue sample. GROa-negative staining in LSCC stromal cells (purple arrow). Original magnification $=\times 40$ in $\mathrm{a} 1, \mathrm{~b} 1$, and $\mathrm{c} 1 ; \times 400$ in a2, b2, and $\mathrm{c} 2$.

CXCR2, the receptor of GROa, interacts with this chemokine with high affinity. In our previous research we demonstrated that elevated expression of CXCR2 is significantly associated with the poor prognosis of LSCC [22]. Thus, although the exact function of GRO $a$ in LSCC remains to be elucidated, it appears reasonable to speculate that the GROa/CXCR2 axis is involved in its pathophysiology. In the present study, the clinicopathological significance of GROa in LSCC was evaluated with a particular focus on its prognostic value.

The results of qPCR showed that the mRNA level of GRO $\alpha$ in LSCC was greater than that in non-cancerous tumoradjacent tissues. The data are consistent with that reported in 

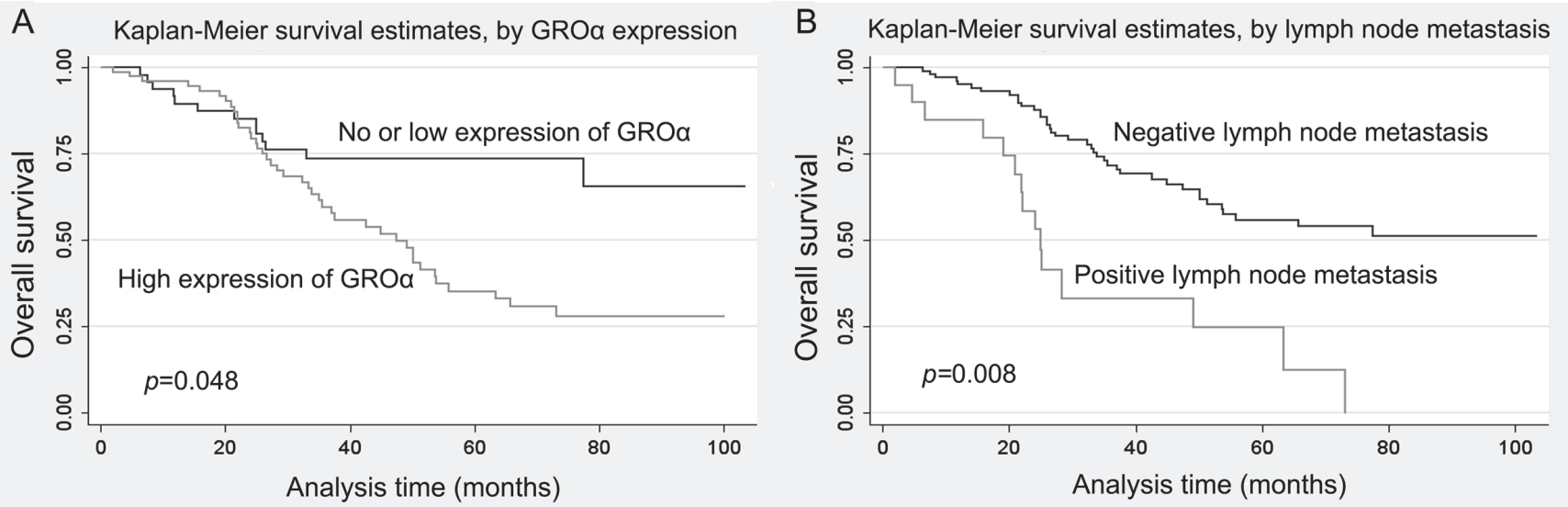

Figure 3. Survival analysis of LSCC patients by the Kaplan-Meier method. A Overall survival rate of patients with elevated (gray line) or low to no GROa expression (black line). B Overall survival rate of patients with positive (gray line) and negative (black line) lymph node metastasis.

a previous study, in which the mRNA expression of GROa was found to be significantly increased in colon adenocarcinoma tissue when compared with that in adjacent normal tissue [27]. We further investigated the expression of GROa protein levels in TMAs prepared from LSCC specimens. Consistent with the results of qPCR, IHC analysis also showed greater GRO $\alpha$ expression in LSCC tissues than in normal tumoradjacent tissues. The IHC staining pattern revealed that GRO $\alpha$ protein was localized in the cytoplasm of cancer cells. It has been previously reported that positive GRO $\alpha$ staining is diffuse and not associated with any specific cell types [28]. The reason for the different localization of GRO $a$ might be because of the use of dissimilar antibodies as well as differences in the samples collected.

Table 2. Univariate and multivariate analysis of prognostic factors in LSCC for overall survival

\begin{tabular}{|c|c|c|c|}
\hline & \multirow{2}{*}{$\begin{array}{c}\text { Univariate } \\
\text { analysis } \\
\mathrm{p}>|\mathrm{z}|\end{array}$} & \multicolumn{2}{|c|}{$\begin{array}{l}\text { Multivariate } \\
\text { analysis }\end{array}$} \\
\hline & & $\mathrm{p}>|\mathrm{z}|$ & $95 \% \mathrm{CI}$ \\
\hline $\begin{array}{c}\text { GRO } \alpha \text { expression } \\
\text { High vs Low }\end{array}$ & $0.001^{*}$ & $0.048^{\star}$ & $1.009-6.267$ \\
\hline $\begin{array}{l}\text { Age (years) } \\
\quad \leq 60 \mathrm{y} \text { vs }>60 \mathrm{y}\end{array}$ & 0.295 & & \\
\hline $\begin{array}{l}\text { Tobacco consumption } \\
\text { Yes vs No }\end{array}$ & 0.100 & & \\
\hline $\begin{array}{l}\text { Alcohol consumption } \\
\text { Yes vs No }\end{array}$ & 0.782 & & \\
\hline $\begin{array}{l}\text { TNM stage } \\
\text { Stage I, II vs Stage III, IV }\end{array}$ & $0.003^{*}$ & 0.098 & $0.934-2.248$ \\
\hline $\begin{array}{l}\text { Lymph node metastasis } \\
\text { Yes vs No }\end{array}$ & $0.001^{\star}$ & $0.008^{*}$ & $1.278-4.999$ \\
\hline $\begin{array}{l}\text { Histopathological grade } \\
\text { High vs Moderate vs Low }\end{array}$ & 0.089 & & \\
\hline
\end{tabular}

GRO $\alpha$ overexpression is also associated with the poor prognosis of various cancers, including breast cancer [29] and colorectal cancer [30]. In our study, increased GROa expression in LSCC was correlated with TNM stage, lymph node metastasis and histopathological grade. Univariate analysis showed that the overall survival of LSCC patients was associated with TNM stage, lymph node metastasis, and GROa expression. Multivariate analysis further revealed that the strong expression of GRO $\alpha$ and positive lymph node metastasis correspond with the poor prognosis of LSCC patients. The Kaplan-Meier curve analysis of LSCC patients with elevated GROa expression and positive lymph node metastasis demonstrated unfavorable overall survival. All the above results suggest that GRO $\alpha$ expression may be associated with the development and progression of LSCC; hence elevated GROa expression may serve as an independent prognostic marker of this disease. Further studies that enroll a larger scale of LSCC clinical samples will be necessary to confirm our results.

In conclusion, this study is the first to evaluate GROa mRNA expression with qPCR and protein expression with TMA in LSCC. Our results showed that elevation of GROa expression correlates with an aggressive malignant phenotype of LSCC. Therefore, GROa may be a valuable and promising prognostic marker of LSCC.

Acknowledgments: This investigation was supported by grants from Science and Technique Development Fund (20120066) of Nantong, Jiangsu, China, and Academy level fund of Nantong Tumour Hosipital, Nantong, Jiangsu, China

\section{References}

1]

JEMAL A, SIEGEL R, WARD E, HAO Y, XU J, et al. Cancer statistics, 2009. CA Cancer J Clin. 2009; 59: 225-49. http:// dx.doi.org/10.3322/caac.20006 
[2] DIRIX P, LAMBRECHT M, NUYTS S. Radiotherapy for laryngeal squamous cell carcinoma: current standards. Expert Rev Anticancer Ther. 2010; 10: 1461-9. http://dx.doi. org/10.1586/era.10.110

[3] BURDUK PK. Association between infection of virulence cagA gene Helicobacter pylori and laryngeal squamous cell carcinoma. Med Sci Monit. 2013; 19: 584-91. http://dx.doi. org/10.12659/MSM.889011

[4] CHEN YF, LUO RZ, LI Y, CUI BK, SONG M, et al. High expression levels of COX-2 and P300 are associated with unfavorable survival in laryngeal squamous cell carcinoma. Eur Arch Otorhinolaryngol. 2013; 270: 1009-17. http://dx.doi. org/10.1007/s00405-012-2275-1

[5] LEFEBVRE JL. Larynx preservation. Curr Opin Oncol. 2012 ; 24: 218-22. http://dx.doi.org/10.1097/ CCO.0b013e3283523c95

[6] MOUNTZIOS G, KOSTOPOULOS I, KOTOULA V, SFAKIANAKI I, FOUNTZILAS E, et al. Insulin-like growth factor 1 receptor (IGF1R) expression and survival in operable squamous-cell laryngeal cancer. PLoS One. 2013; 8: e54048. http://dx.doi.org/10.1371/journal.pone.0054048

[7] SHIN SY, LEE JM, LIM Y, LEE YH. Transcriptional regulation of the growth-regulated oncogene a gene by early growth response protein-1 in response to tumor necrosis factor $\alpha$ stimulation. Biochim Biophys Acta. 2013 ; 1829: 1066-74 http://dx.doi.org/10.1016/j.bbagrm.2013.07.005

[8] LISI S, SISTO M, LOFRUMENTO DD, D‘AMORE M, DE LUCRO R,et al. A potential role of the GRO- $\alpha$ /CXCR2 system in Sjögren's syndrome: regulatory effects of pro-inflammatory cytokines. Histochem Cell Biol. 2013 ; 139: 371-9. http:// dx.doi.org/10.1007/s00418-012-1035-z

[9] CAUNT M, HU L, TANG T, BROOKS PC, IBRAHIM S,et al. Growth-regulated oncogene is pivotal in thrombin-induced angiogenesis. Cancer Res. 2006 ; 66: 4125-32. http://dx.doi. org/10.1158/0008-5472.CAN-05-2570

[10] OGATA H, SEKIKAWA A, YAMAGISHI H, ICHIKAWA $\mathrm{K}$, TOMITA S,et al. GRO a promotes invasion of colorectal cancer cells. Oncol Rep. 2010; 24: 1479-86.

[11] KITTANG AO, HATFIELD K, SAND K, REIKVAM H, BRUSERUD $\varnothing$. The chemokine network in acute myelogenous leukemia: molecular mechanisms involved in leukemogenesis and therapeutic implications. Curr Top Microbiol Immunol. 2010; 341: 149-72. http://dx.doi. org/10.1007/82 2010 25

[12] SZABO P, VALACH J, SMETANA K JR, DVORANKOVA B. Comparative analysis of IL- 8 and CXCL- 1 production by normal and cancer stromal fibroblasts. Folia Biol (Praha). 2013; 59: 134-7.

[13] KAWANISHI H, MATSUI Y, ITO M, WATANABE J, TAKAHASHI T,et al. Secreted CXCL1 is a potential mediator and marker of the tumor invasion of bladder cancer. Clin Cancer Res. 2008; 14: 2579-87. http://dx.doi.org/10.1158/1078-0432. CCR-07-1922

[14] LANE BR1, LIU J, BOCK PJ, SCHOLS D, COFFEY MJ,et al. Interleukin- 8 and growth-regulated oncogene alpha mediate angiogenesis in Kaposi's sarcoma. J Virol. 2002 ; 76: 11570-83. http://dx.doi.org/10.1128/JVI.76.22.11570-11583.2002
[15] VERBEKE H, GEBOES K, VAN DAMME J, STRUYF S. The role of CXC chemokines in the transition of chronic inflammation to esophageal and gastric cancer. Biochim Biophys Acta. 2012; 1825: 117-29.

[16] VERBEKE H, STRUYF S, LAUREYS G, VAN DAMME J. The expression and role of CXC chemokines in colorectal cancer. Cytokine Growth Factor Rev. 2011; 22: 345-58. http://dx.doi. org/10.1016/j.cytogfr.2011.09.002

[17] YANG G, ROSEN DG, ZHANG Z, BAST RC JR, MILLS GB, et al. The chemokine growth-regulated oncogene 1 (Gro-1) links RAS signaling to the senescence of stromal fibroblasts and ovarian tumorigenesis. Proc Natl Acad Sci U S A. 2006; 103: 16472-7. http://dx.doi.org/10.1073/pnas.0605752103

[18] JUNG JJ, NOH S, JEUNG HC, JUNG M, KIM TS, et al. Chemokine growth-regulated oncogene 1 as a putative biomarker for gastric cancer progression. Cancer Sci. 2010; 101: 2200-6. http://dx.doi.org/10.1111/j.13497006.2010.01666.x

[19] BANDAPALLI OR1, EHRMANN F, EHEMANN V, GAIDA M, MACHER-GOEPPINGER S, et al. Macher-Goeppinger S, Wente M, Schirmacher P, Brand K.Down-regulation of CXCL1 inhibits tumor growth in colorectal liver metastasis. Cytokine. 2012; 57: 46-53. http://dx.doi.org/10.1016/j. cyto.2011.10.019

[20] THOMPSON L. World Health Organization classification of tumours: pathology and genetics of head and neck tumours. Ear Nose Throat J. 2006; 85: 74.

[21] SOBIN LH, GOSPODAROWICZ MK, WITTEKIND CH, EDITORS. TNM classification of malignant tumours. 7th. John Wiley \& Sons; 2009.

[22] HAN L, JIANG B, WU H, WANG X, TANG X,et al. High expression of CXCR2 is associated with tumorigenesis, progression, and prognosis of laryngeal squamous cell carcinoma. Med Oncol. 2012; 29: 2466-72. http://dx.doi.org/10.1007/ s12032-011-0152-1

[23] HUANG J, ZHANG J, LI H, LU Z, SHAN W, et al. VCAM1 expression correlated with tumorigenesis and poor prognosis in high grade serous ovarian cancer. Am J Transl Res. 2013; 5: 336-346.

[24] OLADIPO O, CONLON S, O‘GRADY A, PURCELL C, WILSON C, et al. The expression and prognostic impact of CXC-chemokines in stage II and III colorectal cancer epithelial and stromal tissue. Br J Cancer. 2011; 104: 480-7. http://dx.doi.org/10.1038/sj.bjc.6606055

[25] YANG G, ROSEN DG, ZHANG Z, BAST RC JR, MILLS GB,et al. The chemokine growth-regulated oncogene 1 (Gro-1) links RAS signaling to the senescence of stromal fibroblasts and ovarian tumorigenesis. Proc Natl Acad Sci U S A. 2006; 103: 16472-7. http://dx.doi.org/10.1073/pnas.0605752103

[26] BACHMEIER BE, MOHRENZ IV, MIRISOLA V, SCHLEICHER E, ROMEO F, et al. Curcumin downregulates the inflammatory cytokines CXCL1 and -2 in breast cancer cells via NFkappaB. Carcinogenesis. 2008; 29: 779-89. http:// dx.doi.org/10.1093/carcin/bgm248

[27] WEN Y, GIARDINA SF, HAMMING D, GREENMAN J, ZACHARIAH E, et al. GRO alpha is highly expressed in adenocarcinoma of the colon and down-regulates fibulin-1. Clin 
Cancer Res. 2006; 12: 5951-9. http://dx.doi.org/10.1158/10780432.CCR-06-0736

[28] MIYAKE M, LAWTON A, GOODISON S, URQUIDI V, GOMES-GIACOIA E, et al. Chemokine (C-X-C) ligand 1 (CXCL1) protein expression is increased in aggressive bladder cancers. BMC Cancer. 2013; 13: 322. http://dx.doi. org/10.1186/1471-2407-13-322

[29] DIVELLA R, DANIELE A, SAVINO E, PALMA F, BELLIZZI $A$,et al. Circulating levels of transforming growth factor- $\beta$ eta
(TGF- $\beta$ ) and chemokine (C-X-C motif) ligand-1 (CXCL1) as predictors of distant seeding of circulating tumor cells in patients with metastatic breast cancer. Anticancer Res. 2013; 33: 1491-7.

[30] VERBEKE H, STRUYF S, LAUREYS G, VAN DAMME J. The expression and role of CXC chemokines in colorectal cancer. Cytokine Growth Factor Rev. 2011; 22: 345-58. http://dx.doi. org/10.1016/j.cytogfr.2011.09.002 